Open Access

\title{
The reform of the medical welfare system and health equity for the elderly in China: a study in Zhejiang
}

Xiaoting Liu ${ }^{1 *}$ and Hung Wong ${ }^{2}$

\footnotetext{
* Correspondence: xtliu@zju.edu.cn ${ }^{1}$ School of Public Affairs, Zhejiang University, Hangzhou, China Full list of author information is available at the end of the article
}

\begin{abstract}
Health equity is the basic theory of universal health insurance and the objective of reform of the medical welfare system. Based on health equity theory with the perspective of giving priority to disadvantaged groups, this article takes Zhejiang province as an example and adopts a mixed-method approach to explore the effects of the reform of the medical welfare system on health equity for older people. The structural equation model (SEM)-based nonrecursive path analysis demonstrates an improvement of health equity for insured elders of the Basic Medical Insurance for Employees (BMIE) and the Urban Basic Medical Insurance for Residents (UBMIR) as a result of an increased utilization of healthcare. However, there is little difference in terms of the utilization of healthcare and health outcomes between old people insured by the New Rural Cooperative Medical System (NRCMS) and those without medical insurance. This results from the low-level benefits of the insurance policy and defective policy design. A qualitative analysis further discovers the insufficient protection of health equity for several types of vulnerable aged groups in the process of healthcare delivery. Finally, this study advocates the perspective of health equity for vulnerable groups, a transition from emphasizing opportunity equity to stressing outcome equity, and the construction of universal health insurance and long-term care system for the disabled elderly.
\end{abstract}

Keywords: Health equity, Older people, Medical welfare system reform, Structural equation model, Path analysis

\section{Background}

In 2000, China was ranked fourth from the bottom in the World Health Organization's (WHO) evaluation of the performance of member states by fairness in financial contributions to their health systems (WHO 2000). The argument that "the healthcare system reform basically failed" aroused public opinion and led to a heated debate (Ge and Gong 2007). An important reason leading to the collapse of fairness is the excessive market orientation in the healthcare reform along with the transformation of the economic system, resulting in serious damage to citizens' health equity. Data from the Third National Health Service Survey indicated that 48.9 \% of respondents left their illness untreated; the nonhospitalization rate among those that should have been hospitalized was as high as $29.6 \%$; and $76 \%$ of the urban low-income group was uninsured. In terms of medical welfare reform, the governments did not take a leading role, and the governments reduced financial support of medical care (Hu and Deng 2008). Despite the difficulties in the

(C) 2016 Liu and Wong. Open Access This article is distributed under the terms of the Creative Commons Attribution 4.0 International License (http://creativecommons.org/licenses/by/4.0/), which permits unrestricted use, distribution, and reproduction in any medium, provided you give appropriate credit to the original author(s) and the source, provide a link to the Creative Commons license, and indicate if changes were made. 
healthcare system reform, a new round of reforms launched in 2009 prioritized the improvement of the medical welfare system.

Since the 1990s, medical insurance has entered into a phase of rapid development and decommercialization when social policies were initiated and improved to change the inequitable healthcare system (Wang 2008). The establishment of the Basic Medical Insurance for Employees (BMIE) plan in 1998 marked the fact that China had moved from a traditional medical welfare system toward social medical insurance. Over the past decades, the social medical welfare system reform, centered on medical insurance reform, received priority for development among a variety of social policies and acted as a pioneer in achieving the objective of health equity. The report to the 18th National Congress of the Communist Party of China also changed the guidelines of social medical insurance from the previous wide coverage to universal coverage; this meant not only universal coverage of health services but also full coverage of the entire population, a difference that represented the transformation of ideology (He 2013).

The reemphasis on and further improvement of equity in national-level macrostrategies reflects the fact that the Chinese government has acknowledged its responsibility. The 11th Five-Year Plan in 2005 proposed that China would place more emphasis on social equity so that residents would be able to share the success of reform and development. The new healthcare reform program initiated in 2009 proposed that the basic medical welfare system should achieve comprehensive coverage for urban and rural residents by 2011, while local governments at all levels planned to invest 850 billion yuan. Quite a large amount of the fund would be used to extend medical-insurance coverage and increase reimbursement benefits to the insured population. In particular, the investment in the New Rural Cooperative Medical System (NRCMS) and the Urban Basic Medical Insurance for Residents (UBMIR) would account for $50 \%$ of medical expenditures in the central government budget. In 2010, the 12th Five-Year Plan established a comprehensive basic medical welfare system for urban and rural residents, with the goal of paying much more attention to protect people's well-being and promote social equity and justice. The Report to the 18th National Congress of the Communist Party of China in 2012 reemphasized safeguarding social fairness and justice and gradually establishing a social security system focusing on equal rights, equal opportunities, and fair rules for all. The ultimate aim is to accelerate the establishment of a universal medical insurance system and reshape the theoretical framework of health equity through social medical welfare system reform.

While satisfied with the reform's goal to repeal equity, we should not neglect the existing deep inequity in the medical welfare system, such as the severe disparities in health benefits for participants in different medical insurance plans, and the related inequality with respect to healthcare utilization. Health equity is difficult to accomplish in China, while high costs of serious illness is still a risk for both urban and rural uninsured residents. As described by the British scholar Peter Townsend, the "medical poverty trap" still exists even after the reform; some social disadvantaged groups are trapped in their inability to afford medical expenses (Whitehead 2011). Except for empirical studies that reveal health inequality, equitable healthcare service has not been put into effect in practice, which further exacerbates outcome inequity for vulnerable older people. Looking back on past medical welfare system reform, China underwent the process of change from the loss of health equity to its reconstruction, during which 
it had to fulfill the transition from proposing slogans on health equity to implementing new policies.

This article aims to define health equity in theory and proceeds from the social justice theory of giving priority to disadvantaged groups to establish the theoretical framework of process- and outcome-based health equality. Taking the example of the elderly with higher demand for healthcare, we introduce structural equation model (SEM)-based nonrecursive path analysis to explore the relationships between different medical insurance plans, healthcare utilization, and health outcomes in order to answer the question of whether the increasing use of medical care brought by the extended coverage of medical insurance improved the health outcomes for disadvantaged older people. In order to meet the healthcare needs of the disadvantaged elderly, this article analyzes, with the help of the qualitative research method, the impacts of the reform on health equity in the specific process of healthcare service delivery. Finally, the article proposes an outcome-based health-equity framework, advocating an integrated approach in framing the policy directions for the universal health insurance system.

\section{Theories and impact factors of health equity}

Over the past three decades, the phrase "health equity" developed from a sensitive term embedded in western ideology to a popular concept. Related studies on health equity have increased tremendously, while people are increasingly committed to reducing health inequity by means of social policy and welfare programs (Gwatkin et al. 2005).

\section{Health equity: from the perspective of opportunity equity to process and outcome equity}

Among previous empirical studies, the terms "health equality" and "health equity" were often not distinguished in their use (Goddard and Smith 2001; Schoen and Doty 2004). Based on the theories of equality, equity, and social justice, this study discusses the issue of health equity. This is a value-based concept that claims health equity is of more importance for vulnerable groups. In addition, health equity is a multidimensional concept that includes the three dimensions of opportunity, process, and outcome equity.

WHO defines health equity as the absence of avoidable or remediable health differences among groups of people, whether those groups are defined socially, economically, demographically, or geographically. Health inequities involve more than inequality with respect to health determinants and access to the resources needed to improve and maintain health outcomes, as well as a failure to avoid or overcome inequalities that infringe on fairness and human rights norms (WHO 2000). The World Bank believes that health inequality is mainly reflected in some existing differences between advantaged and disadvantaged social groups, such as lower income, fewer medical insurance benefits, and worse living conditions for the latter, rather than only differences in preferences. This so-called health inequity refers to avoidable, unnecessary, and unfair differences (Whitehead 1992); these differences should hence be regarded as inequity rather than inequality (Wagstaff and Van Doorslaer 2000).

There are certain differences between health equity and health inequality in theory. Equality is a value-free concept, while equity is value-based. Group inequality receives more attention in the field of social welfare, which is usually the root of social conflicts 
and confrontations. The objects of equality, such as income and asset, right and freedom, opportunity, well-being, or capability, are in themselves neither good nor bad; equality on one thing is likely to cause inequality in other things or in other aspects (e.g., opportunity equality may bring about outcomes inequality). The theoretical principles of equality have their pros and cons (Hayek and Hamowy 2013; Crocker 1977; Rawls 1971; Sen 1992). This study mainly considers equality among groups; the object is health, which is premised on obtaining income from work and assets, the necessity for realizing rights and liberties, and the essential qualities for obtaining basic capabilities and accomplishing certain achievements.

This study is based on the theory of social justice by John Rawls, which is devoted to achieving equality for the underclass group and prioritizing vulnerable groups in distributing medical benefits and resources, thus improving their health outcomes as much as possible. Although Rawls did not list health as a basic social good, Daniels et al. (1999) extend Rawls's theory and considers from the perspective of opportunity equity that encompasses health. Two points are emphasized in Rawls's principles of justice: one is opportunity equity (each person is to have an equal right to the most extensive basic liberty compatible with a similar liberty for others), and the other is the difference principle, i.e., improving the well-being of the least advantaged group as much as possible (Rawls 1971). In the social medical insurance system, the disadvantaged social group should share equitable benefits; by the theory of expected utility, the demand for insurance reflects the degree of risk aversion and certainty for incomes (Wagstaff 2000). Facing the risk of illness, the vulnerable group will express stronger risk aversion since the vulnerable or the poor are not able to afford healthcare services without insurance. In practice, the principle of giving priority to disadvantaged groups has been successfully implemented in the national medical insurance systems of certain countries or regions, such as Taiwan, such that the lowest income group receives the most insurance benefits. As individual income increases, insurance benefits decrease, while the highest income group receives the least insurance benefits compared to their contributions to the insurance fund (Huang et al. 2007).

Of course, the opportunity equity stressed by Rawls provides the foundation but is not adequate for interpreting social justice. In social medical welfare reform, the supposedly universal coverage of medical insurance for all social groups in fact excludes uninsured people who are unable to afford the premium, and hence fails to fundamentally fulfill the objective of justice. Given some of the problems in addition to opportunity inequity that exist in the medical welfare system - urban and rural separation, group segmentation, and regional imbalance-process equity and outcome equity have not yet received much attention, which further compromises the effects of reform.

\section{The effects of medical insurance on health equity}

Outcome-based health equity should include not only equity in healthcare utilization but also equity in health status. In empirical studies, the impact of medical insurance on health equity was developed to explore the relationship between medical insurance and the healthcare utilization and the relationship between medical insurance and health status. The extended coverage of medical insurance improved older people's access to healthcare services (Freeman et al. 2008; Wagstaff et al. 2009), increased the 
utilization rate of healthcare services (Decker and Rentier 2004; Liu et al. 2011), and raised the expenditures on healthcare (Davis 1991; Meer and Rosen 2004). However, a major controversy existed in regard to the direct association between medical insurance and health status. Some research indicates that the expansion of medical insurance helps to improve health status (Card et al. 2008; Lichtenberg 2002; Huang and Gan 2010), while others find that extension of medical insurance does not necessarily improve health status (Brown et al. 1998; Levy and Meltzer 2004).

In China, the Basic Medical Insurance program is not a universal entitlement but rather reflects differences in social classes. Retired older people enjoy the highest benefits through BMIE and free medical service, while urban and rural residents in UBMIR and NRCMS are covered by insurance programs with low benefit packages according to their lower premium contributions. This reveals the fact that deep inequity still exists in the current Basic Medical Insurance system. In other words, one major challenge is the significant differences in benefit packages among the elderly in divergent social groups (Lv 2009), resulting in unfairness in the utilization of healthcare services and in health outcomes (Liang et al. 2003; Wang and Long 2010; Gao et al. 2011). We can conclude that high medical-insurance coverage and inequitable benefits coexist, whereas equity in healthcare utilization is weakened due to a higher individual burden of disease (Wang et al. 2005).

Few previous empirical studies consider the relationship among medical insurance, healthcare utilization, and health equity at the same time. The objective of medical insurance is to reduce the individual financial burden of illness and to improve equity in healthcare utilization; the ultimate goal of equity in healthcare is to promote equity in health outcomes. This study thus initiates the idea that the mechanism by which medical insurance influences health outcomes is through an indirect effect on healthcare utilization, which should be treated as a mediator between medical insurance and health outcomes. In the specific process of health-service delivery, implementation of the medical welfare system profoundly influences equity in health outcomes for the disadvantaged elderly group. In addition, this study uses qualitative analysis to introduce subjective experiences of receiving healthcare services among disadvantaged elder people and discusses how the reform of the social welfare system affects the health equity of older adults.

\section{Methods}

Although the reform of medical insurance extended coverage, increased options, and promoted opportunity equity, the actual effect of medical insurance on health outcomes through intervention in healthcare utilization is still unclear. According to the theoretical framework of the current study, our evaluation of reform also focuses on process equity in utilizing healthcare services among the disadvantaged elderly as well as equity in health outcomes. The study introduces a mixed quantitative-andqualitative method.

\section{Data and measurements in quantitative study}

The data used for quantitative analysis came from the 2010 Survey of the Aged Population in Urban/Rural Regions in Zhejiang province. The survey was collected by the China 
National Committee on Aging and adopted the probability proportional to size sampling (PPS) approach. In Zhejiang province, 12 towns and 12 counties were sampled; 144 residential committees and 150 villager committees were selected within towns and counties, respectively; ten families were randomly sampled from each residential or villager committee; and the older people to be interviewed were determined by the Kish table in each family. The total sample size of old people aged 60 and over was 2940 (1440 in urban areas and 1500 in rural areas), totaling about $0.5 \%$ of the total aged population in Zhejiang.

With regard to the conceptualization and operationalization of types of medical insurance, this study only involved social medical insurance programs, including BMIE (38.0 \%), UBMIR (9.5\%), NRCMS (49.5\%), and the uninsured (3.0\%) (uninsured was the reference group), but excluded commercial medical insurance plans that were not in the social medical insurance system.

In western literature, healthcare utilization is usually operationalized into multiple dimensions. For example, some studies classify utilization by the number of times one receives healthcare services in a certain period of time and the related medical expenses (Diehr et al. 1999). Other studies categorize utilization by purpose, type, and unit of analysis (Anderson and Newman 2005). In Chinese literature, utilization is often operationalized into three dimensions: frequency of doctor visits in a certain period of time, days of hospitalization, and healthcare expenditures (Liu et al. 2012). The measures of these three dimensions encompass not only the type of healthcare, outpatient and inpatient services, but also the amount of healthcare services. Therefore, this study adopts these three variables to operationalize healthcare utilization as "frequency of doctor visits in the past year," "days of hospitalization in the past year," and "total healthcare expenditures in the past year," averaging 2838 yuan (logarithm of healthcare expenditures was included in the model). We constructed separate path models for these three dimensions and obtained robust and consistent results of which only the result of path analysis where "healthcare expenditure" was treated as a mediator is reported in this paper.

Health outcomes were reported by self-reported health status, recorded as a fivepoint Likert scale from "very bad" to "very good" ("very good" 6.6 \%, "good" $24.0 \%$, "general" $41.0 \%$, "poor" $16.5 \%$, "very poor" $1.8 \%$ ). In analyzing the associations between medical insurance, healthcare utilization, and health status, the great challenge lays in the time lag for health outcomes, that is, the delayed effects. Some studies explore health inequity among older people from the perspective of life course and reveal that the reason for inequity is the accumulated disadvantages across different life stages for the frail elderly (Pavalko and Caputo 2013; Cheng 2004; Xu and Li 2014) but not necessarily the disparities in medical insurance. However, the exploration of the effect of medical insurance on health status can be measured through experiments or quasiexperiments and is limited to a certain range due to the complexity of health (Card et al. 2008). We realized the potential limitations of measuring the relationships among medical insurance, healthcare utilization, and health level using cross-sectional data. To make up the shortfall, we introduced a SEM-based path analysis model that could simultaneously measure the bidirectional relationship between healthcare utilization and health status. The hypothesis was that healthcare utilization would improve health level, and poor health status required much more healthcare utilization.

The control variables in the model included age, education, family income, and number of chronic diseases. Among them, age ranged from 60 to 98, with an average of 72 . 
Education consisted of five levels: "illiteracy" made up $35.3 \%$, "primary school" $35.8 \%$, "middle school" $16.1 \%$, "high school" $7.9 \%$, and "college and above" $4.9 \%$. Considering family size, household income was calculated by the "modified equivalence scale" of Organization for Economic Co-operation and Development (OECD) (Hagenaars et al. 1994), with the formula "equivalent household income $=$ household income/ $[1+0.5$ (spouse in the same household + number of parents in the same household + number of sons in the same household + number of daughters-in-law in the same household + number of daughters in the same household + number of sons-in-law in the same household) +0.3 (number of grandchildren in the same household)]", with an average of 13,496.7 yuan per year. The number of chronic diseases ranged from zero to 16, and each old person had an average of two chronic diseases. In addition, household registration was an important indicator for the medical welfare system in China (Hu 2003), but $90.3 \%$ of older people with rural household registration are insured by the NRCMS, which was excluded from the model because of a problem of multicollinearity.

\section{Sample selection in qualitative study}

In order to answer the question of why old people who are enrolled in different medical insurance plans have divergent effects on their health status through healthcare utilization, we chose village A, county B, and city $C$ in Zhejiang province and selected six samples of disadvantaged elderly who met certain criteria (60 years old or above, bad health status, low family income, and with different basic medical insurance or not covered by insurance). We conducted in-depth interviews with these individuals, and a ten-person focusgroup interview was conducted as well. In addition, the staff in the Department of Civil Affairs and the Department of Medical Insurance was interviewed to assess health equity in the reform. Data collected through the qualitative method was organized with a thematic analysis.

\section{Results and discussion}

\section{Path-analysis modeling and estimation}

This study adopted a structural equation model to set up a nonrecursive path-analysis model, using the exploratory analysis approach of maximum likelihood estimation to examine the associations among different insurance plans, healthcare expenditures, and health status with the help of AMOS 17.0 software. This approach offers two advantages: first, we could identify the best model from all possible models; second, we were able to measure the backtracking relationship between healthcare expenditure and health status. The three indicators measuring model goodness of fit were chi-squared statistics $X^{2}$ (chi-squared $p$ value $>0.05$ means the model has a good fit), compared fit index (CFI $>0.90$ indicates a good fit for the model), and the root-mean-square error of approximation (RMSEA $<0.1$ represents a good fit) (Rong 2009).

We implemented the exploratory model-based analysis and obtained the optimal model, as shown in Fig. 1 (coefficients for extraneous variables are reported in Table 1). The Browne-Cudeck criterion (BCC) for the best model is 0.000 , indicating that the model had better goodness of fit than other models (Burnham and Anderson 1998). In addition, the chi-squared statistic $\left(\chi^{2}=2.828, d f=5, p=0.727\right)$ showed that we failed to reject the model, and both CFI (1.000) and RMSEA 


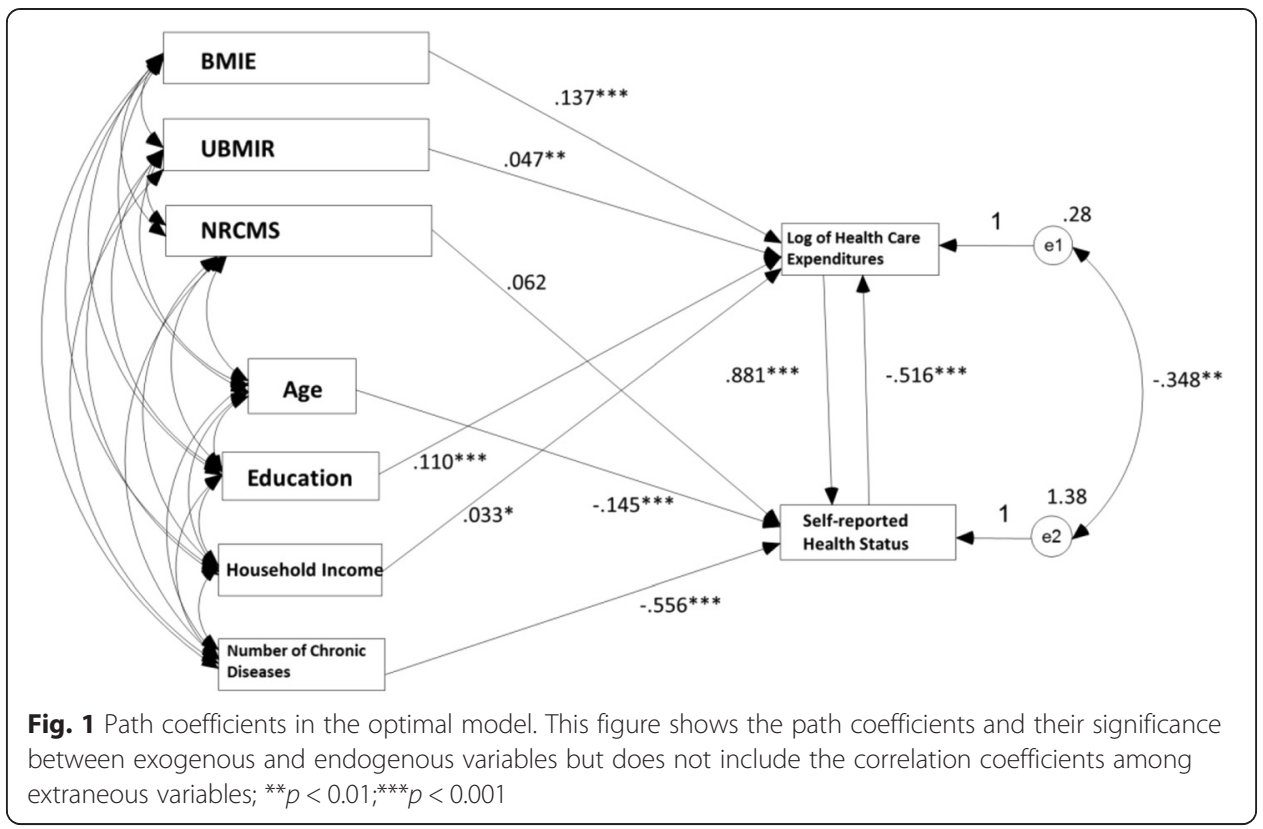

(0.000) reflected a good model fit. The direct and indirect effects of antecedent variables on healthcare expenditures and health level are presented in Table 2.

In Fig. 1 and Table 2, we present estimates of direct and indirect effects of different types of social medical insurance on healthcare expenditures and health outcomes, controlling for all other variables. BMIE and UBMIR did not affect health outcomes directly but indirectly through the mediator of healthcare expenditures. Compared to the aged group with no insurance, older people insured by BMIE and UBMIR had higher healthcare costs and then maintained better health outcomes. By comparing the total effects, we found that BMIE (0.094) had greater effects on healthcare expenditures than UBMIR (0.033). Nevertheless, a statistically significant effect for NRCMS on healthcare expenditures did not exist; the standardized path coefficient (0.062) of the direct effect from NRCMS on self-rated health was not statistically significant. Although basic medical insurance achieved nearly universal coverage, there were still large disparities in benefit packages for different insurance plans; in particular, older people insured by NRCMS did not demonstrate a better health outcome than that of the uninsured.

Table 1 Correlations among exogenous variables (standardized correlation coefficients)

\begin{tabular}{|c|c|c|c|c|c|c|c|}
\hline & BMIE & UBMIR & NRCMS & Age & Education & $\begin{array}{l}\text { Household } \\
\text { income }\end{array}$ & $\begin{array}{l}\text { Number of chronic } \\
\text { diseases }\end{array}$ \\
\hline BMIE & 1 & & & & & & \\
\hline UBMIR & $-0.234^{* * *}$ & 1 & & & & & \\
\hline NRCMS & $-0.747^{* * *}$ & $-0.308^{* * *}$ & 1 & & & & \\
\hline Age & -0.016 & 0.020 & -0.015 & 1 & & & \\
\hline Education & $0.557^{* * *}$ & $-0.050^{* *}$ & $-0.464^{* * *}$ & $-0.189^{* * *}$ & 1 & & \\
\hline Household income & $0.116^{* * *}$ & -0.013 & $-0.096^{* * *}$ & 0.007 & $0.133^{* * *}$ & 1 & \\
\hline $\begin{array}{l}\text { Number of chronic } \\
\text { diseases }\end{array}$ & $0.145^{* * *}$ & -0.006 & $-0.136^{* * *}$ & $0.155^{* * *}$ & $0.041^{* *}$ & 0.009 & 1 \\
\hline
\end{tabular}


Table 2 Direct effect, indirect effect, and total effect of medical costs and health level

\begin{tabular}{lllll}
\hline Outcome variables & Determinants & Direct effects & Indirect effects & Total effects \\
\hline Log of healthcare expenditures & BMIE & 0.137 & -0.043 & 0.094 \\
& UBMIR & 0.047 & -0.015 & 0.033 \\
& NRCMS & 0 & -0.022 & -0.022 \\
& Age & 0 & 0.052 & 0.052 \\
& Education & 0.110 & -0.034 & 0.076 \\
& Household income & 0.033 & -0.010 & 0.023 \\
& Number of chronic diseases & 0 & 0.197 & 0.197 \\
& Log of healthcare expenditures & 0 & -0.312 & -0.312 \\
& Self-reported health status & -0.516 & 0.161 & -0.355 \\
& BMIE & 0 & 0.083 & 0.083 \\
Self-reported health status & UBMIR & 0 & 0.029 & 0.029 \\
& NRCMS & 0.062 & -0.019 & 0.042 \\
& Age & -0.145 & 0.045 & -0.100 \\
& Education & 0 & 0.067 & 0.067 \\
& Household income & 0 & 0.020 & 0.020 \\
Number of chronic diseases & -0.556 & 0.174 & -0.382 \\
& Log of healthcare expenditures & 0.881 & -0.275 & 0.606 \\
Self-reported health status & 0 & -0.312 & -0.312 \\
\hline
\end{tabular}

From the bidirectional relationship between healthcare expenditures and selfreported health status estimated by the path model, we observed that increase in healthcare expenditures had positive effects on improvement of health outcomes, controlling for insurance, socioeconomic status, and demographic variables. The total effect $(0.606)$ was greater than the total effect of improving health on reducing healthcare expenditures $(-0.355)$. Maintaining a certain amount of healthcare costs was helpful in significantly improving the health outcomes of older people. It plays an important role in improvement of health equity if the benefits for the elderly covered by NRCMS and UBMIR are increased. In addition, the rise of socioeconomic status (education and household income) also improved health outcomes through increasing healthcare expenditures (the mediator), and contribution from education to health (total effect 0.067) was greater than that from household income to health outcomes (total effect 0.020). Increase in socioeconomic status was still a crucial factor in improving health equity for vulnerable aged groups.

In summary, the SEM-based path analysis uncovered the relationship among different insurance types, healthcare expenditure, and health outcomes, suggesting an effective intervention approach for medical insurance reform. An increase in medical insurance reimbursements would provide a significantly positive effect toward health outcomes for the vulnerable elderly, such as the NRCMS-insured group. Although this effect was indirect, it was far from negligible. The path analysis, based on controlling for social deterministic factors, demonstrated the essential inequity in the social medical insurance system, which is a systematic barrier for older people.

The quantitative analysis suggests that medical insurance affects health equity through healthcare services, and different insurance programs have different effects on health outcomes. This study required continued exploration beyond the models, 
the mechanisms by which different medical insurance programs affect processbased and outcome-based health equity through specific delivery of health services, and to answer the question why NRCMS failed to improve health status through effective utilization of healthcare services. For this reason, it was necessary to introduce the subjective experiences of the disadvantaged elderly in the process of medical treatment and to investigate the factors that caused health inequity among older people during the reform of the medical insurance system.

\section{The opportunity-based reform of the medical welfare system}

The "opportunity equality" proposed by John Rawls in A Theory of Justice received attention in policy making during the reform of the medical welfare system in China, which was reflected in enhancing participation in medical insurance programs. Since the new healthcare reform in 2009, Zhejiang province was among the first to explore enhancing equity in the health and welfare system, including the integration of the medical welfare system, coordination of medical insurance in urban and rural areas, pooling funds for outpatient costs, and reform of the medical assistance system for the poor. Among these ideas, the most advocated was to establish a multilevel welfare system, and older people could themselves choose which insurance plan to join, regardless of urban or rural household registration status. This broke the rigid institutional rules regarding the segregation between rural and urban areas. This reform also set three levels of benefit packages, high, medium, and low, and allowed free choice according to the individual's ability to pay. However, this option based on financial ability still resulted in disadvantaged groups choosing the lower level of benefits due to affordability.

Moreover, the public budget took responsibility of payments for insurance premiums for disadvantaged older people in order to help them participate in medical insurance plans, ensuring that they would not be excluded from the medical welfare system due to unaffordability. Staff in the governments also considered governments' financial responsibility for elders' healthcare needs as a priority, reflecting opportunity equity.

For the financing aspect, the retired do not pay any premium, but receive more financial subsidies. For instance, the elderly who participate in the medical insurance for urban and rural residences pay lower than 30 percent of the total premium. Moreover, for poor, low-income families, the disabled, five-guarantees and three-no people, financial assistance helps pay all. (Staff 1, interviewee W from a Department of Medical Insurance)

The frail elders are more likely to access healthcare services if they are protected by medical insurance! For elders from low-income families, medical assistance also helps increase their health rights. This institution is certainly a guarantee for them. (Staff 2, interviewee P from Department of Civil Affairs)

It was very important to improve health equity by enabling disadvantaged groups who have low ability to pay to obtain equal entitlement. However, this was just the beginning in that coverage did not necessarily mean old people shared equal benefits 
from medical insurance reimbursements, or from high-quality healthcare services. The essential equity was that vulnerable groups would receive equal treatment during the process of healthcare delivery and obtain priority in insurance reimbursements. The social insurance system emphasized equal contribution and benefits, and the setup of option rights also enhanced "higher payment, more benefits" among both urban and rural residents. However, the achievement of opportunity equity did not solve the problem of inequality in receiving healthcare services for frail elders with lower socioeconomic status. The basic responsibility of the government should be transferred from opportunity equity to process- and outcome-based equity.

\section{Subjective experiences of disadvantaged elderly in process and outcome inequity}

From thematic analysis of qualitative data, we found that disadvantaged older people constructed the perspective of inequity through comparing their benefits with those of other groups. In listening to the descriptions of diseases and narratives of daily life for vulnerable elders, the word "bitter" appeared frequently, such as "very bitter," "so bitter," and "too bitter." Despite their serious diseases and difficulties, the disadvantaged elders did not attribute their hardships to inequity, or demanded social rights. They used phrases such as "have no choice" or "unfortunate" to express their acceptance and helplessness. Old people thought that they were "better off without diseases," "unfortunate if unhealthy," and "hopeless if [they] fall ill." These negative perspectives on disease clearly indicated that they regarded diseases as individual risks rather than social inequity, and did not rely on the government or society. However, this does not mean that older people do not have any expectation of health rights. Instead, the feeling of inequity in regard to the health of the frail elderly was based on a comparison with other aged groups, reflected in their experiences, that governments and hospitals discriminated against them in terms of policies and services. The vulnerable elders were relatively sensitive to this difference and even angry at some experienced inequality. All in all, health inequity was constructed based on comparisons among the three groups: between rural and urban elders, between the retired elderly and cadres, and between covered and uncovered groups by the medical assistance system, which revealed deep inequities in the reform of the medical welfare system.

\section{A comparison between urban and rural: inequity in social welfare and health outcomes}

Due to the limited benefit packages provided by NRCMS, insured rural residents and their families had to pay a considerable amount of out-of-pocket costs for healthcare services. For elderly rural residents, the disparities in medical welfare were only part of the social welfare difference between rural and urban areas. Compared to older urban residents, the most significant inequity for rural residents was fewer social welfare benefits, such as pensions and medical insurance. These differences directly determined their different attitudes toward diseases and decision making in the use of healthcare. Older people were afraid of serious illnesses, yet older people in rural areas tended to go to the hospital only for relatively severe diseases but ignored less-serious diseases. The formation of the disadvantaged position was rooted in the different treatment of older people in rural and urban areas, which impaired the benefits and health status of the former. Their attitude toward diseases was described as "going to hospital only if the pain is intolerable," and 
"ignore it if it is not painful." The elderly in rural areas usually compared their welfare benefits with that of urban elders with the words "of course much worse," and "there is a great gap."

F in Village $\mathrm{H}$ in County A is sixty-seven years old and has been suffering for three years from hemiplegia caused by a stroke. His family includes five people and lives on a salary of 2,400 yuan per month earned by his son and daughterin-law as contract workers in a factory. When asked to compare his situation to urban residents in terms of hospital visits, F said, "How can I have enough money for a hospital visit? I buy and take medicines. I go to the hospital only if I cannot get up. I am not going to the hospital as long as the illness is tolerable. Had I spent this money today, I would have no money tomorrow. This is not like the elders in urban areas; those older people have an allowance after retirement. You can get it after you use it up. It is not the same in rural areas; we only get 100 yuan allowance per month [allowance for old people in rural areas]. Medical insurance covers at least 70 percent of the costs in urban areas, but we have to pay ourselves." (Interviewee no. 5, old person F in county A)

The fewer benefits of medical insurance limit the contributions to improving health equity for rural residents. Even worse, older people in rural areas had worse health outcomes for the same disease due to their disadvantaged welfare status. For instance, old man L (80 years old) had a stroke problem similar to F in county A but was an urban resident covered by BMIE. Aunt U, Mr. L's daughter-in-law, said: "When he was sent to the hospital, we invited a doctor from a big hospital in Shanghai, who drilled two holes in his head and drained the congestion. He is now the same as a healthy person. We did spend lots of money, but his insurance covered much of it. He also has a retirement pension of about 4000 yuan per month. We do not have any financial burden." (Interviewee no. 7, old person L in county A).

The above analysis demonstrates the fact that different health outcomes from similar disease conditions is caused by the inequitable distribution of medical resources between rural and urban areas; also, it reflects the unequal benefits from BIME and NRCMS, and even the feeling of insecurity experienced by older people in rural areas from unequal social welfare provision.

\section{The comparison between the ordinary elderly and retired cadres: Unequal status}

Besides the disparities between rural and urban areas, another interesting finding was that the ordinary elderly were likely to compare themselves to retired cadres regarding their health benefits. This difference was an accumulated disadvantage of occupation and social status since early life. Compared to the urban-rural disparity, the disadvantaged elderly were even more dissatisfied about the inequities caused by social class, which were reflected in the discrimination of doctors and nurses against the elderly with lower socioeconomic status. Due to a large disparity in the benefits paid by different medical insurance plans, rural older people emphasized the differential treatment of cadres and farmers in the process of healthcare services, and used phrases such as "incomparable with cadres" to describe the inequity 
in medical welfare between the two groups. Regarding inequity during the medication process, an old man who was a land-lost farmer in county B said:

ZC: The benefits [of medical welfare] are apparently different! Cadres receive different treatment! It is also different in the arrangement of ward beds. When we requested inpatient services, they said no bed [in the hospital]. If it were cadres, they would have available rooms. Even if you are accepted by the hospital, they only give you the worst room and bed. However, if cadres come, we are asked to leave even if we are still in need of inpatient services.

LZ: Absolutely, sometimes they let us stay in corridors.

WZ: Not only the sick but healthy cadres are staying in the hospitals. (Focus-group interview in county B)

The specific reason for inequity was that the best medical welfare benefits and high coverage were provided to retired cadres, who also had the highest ability to pay for healthcare. In community $\mathrm{G}$ of city $\mathrm{C}$, the researcher interviewed a couple, $\mathrm{M}$ and $\mathrm{N}$. $\mathrm{N}$ was a retired worker suffering from uremia. He needed chemotherapy three times per week, and $95 \%$ of the expense was covered by his medical insurance. Their dialogue conveys the reason for inequity in healthcare services:

M: Some retired cadres stay in the hospital for a long time. Some of them get a pension of more than ten thousand yuan per month.

$\mathrm{N}$ : Yes, many of the people [staying in the hospital] who are benefiting from free health services are all cadres. Even when these ward beds are empty, other people cannot afford them. The price of the hospital bed for my husband was 500 yuan per night, which is much more expensive than a hotel.

M: Hospitalization for cadres is free, all the costs are covered by the governments. $\mathrm{N}$ : Some ward beds can cost 1,000 yuan per night. How terrible! We told them we wanted to get a worse bed rather than a good one. He said there was no worse one. We have to bear it, no choice, since we needed a surgery. (Interviewee no. 2, old couple $\mathrm{N}$ in city $\mathrm{C}$ )

Despite the gap between urban and rural areas gradually reducing, as long as the reform in medical welfare was being carried forward, the inequities between the ordinary elderly and cadres did not decrease but became a fundamental factor that affected the understanding of health inequity for vulnerable elders. The equity in health outcomes could hardly be improved if the traditional free medical service system for cadres was only nominally integrated into BMIE but did not substantively decrease the relative disparities in medical benefits. One possible pathway was to increase governmental healthcare expenditures in the reform to make up for these disparities. From the perspective of process equity, medical insurance should be treated as an agent for insured people and carry out the function of cost control and quality supervision, thus eliminating the discrimination against disadvantaged elderly in healthcare services. This medical welfare reform definitely called for assistance from the healthcare system reform; in turn, 
the difficulty of promoting the latter inevitably constrained the effectiveness of the former.

The comparison between covered and uncovered elders from the minimum living standard program: who is more vulnerable?

In explaining health equity through the comparative perspective of disadvantaged older people, we found another phenomenon: older people who were only covered by medical insurance but did not qualify for the minimum living standard (MLS) plan were even more disadvantaged than poor elders covered by MLS. They experienced the negative effect of MLS on health equity. When asked, "Why did you not request social assistance such as medical assistance or MLS since you are living with many difficulties?" the most frequent answer was, "Older people who have sons or daughters do not qualify for being covered by MLS." Some social assistance programs were based on the qualification of MLS, which subsequently ensured other assistance such as in medicine, housing, or education. Zhejiang had a relatively developed medical assistance system that was independent of the qualification of MLS and aimed at covering older people who were really in need of medical assistance. However, the problem was stigma-old people did not want to be labeled as poor.

The abovementioned old person $\mathrm{N}$, who was suffering from uremia and financial difficulties, was not covered by MLS. When asked why he did not apply for MLS or medical assistance, N said: "We are mentally strong. We have bad living conditions but do not want to apply for MLS, only because as older people we need dignity" (Interviewee no. 2, old couple $\mathrm{N}$ in city $\mathrm{C}$ ).

Similarly, the previously mentioned paralytic F in county A was not covered by medical assistance since he did not qualify for MLS. The cousin of F said: "His family has the worst conditions in the village. He is the burden of the family. They requested MLS from the village committee, but it is not useful. He has a son, so that could not cover him!" (Interviewee no. 5, old person F in county A).

Actually, interviewees misunderstood the MLS, which did not exclude older people who had children but was based on a means-test approach of household income over the minimum living line. However, this misunderstanding still indicates that this system did not satisfy the real needs of all disadvantaged older people. It excluded the elderly who de facto needed assistance through excessively rigid rules and unreasonable institutional settings. A proper design of social assistance as a security baseline would not only relieve the financial burden of vulnerable groups but also alleviate their psychological pressure and enhance their confidence in life. The MLS-qualified elderly were likely to positively interpret the equity, unlike MLS-unqualified older adults who understood it from a negative aspect.

Mr. T from community $\mathrm{G}$ of city $\mathrm{C}$ suffered from neural muscular atrophy. He and his wife were small-business owners and did not participate in any medical insurance plan. This previously rich family was totally changed due to expensive medical fees and the loss of ability to work. They spent all their savings to treat the disease. They and their child lived in an old apartment of only $20 \mathrm{~m}^{2}$ and used wood boards to cover the broken window in their room, allowing little sunshine in the daytime. Dim light bulbs flickered, keeping them from seeing clearly in the room. The community committee helped them apply for MLS and enrolled them in social medical insurance at no cost. Regarding their understanding of equity, Mr. T's wife said: "The medical insurance and MLS for my family is 
fair. Without it, our life is even bitterer. After getting the MLS certificate, all the medical insurance premiums are covered by the governments, and the benefits are exactly the same as those of employees. We used to pay all the medical bills and could not afford it at all ... now the pressure is much lighter!" (Interviewee 1, old person $\mathrm{T}$ of city $\mathrm{C}$ ).

Older people who qualified for MLS felt that they received relatively fair benefits, contrasting drastically to the feelings of those who did not qualify. It was appraised as social assistance that improved the feeling of health equity for those elderly who qualified for MLS. However, the key problem was how to improve the medical assistance system and increase the fiscal responsibility of governments, enabling more disadvantaged older people such as $\mathrm{F}$ and $\mathrm{N}$ to be covered. The medical assistance system should not only cover families with low income or those linked to MLS but also be open to all patients with severe diseases with high medical costs, based on the basic health rights and needs and the respect of life, in order to disperse the remaining risk after receiving reimbursements from medical insurance.

In summary, the medical welfare system has been improved over the past many years and basically achieved opportunity equity through universal coverage of medical insurance for all social groups. Nevertheless, the equity understood by the disadvantaged elderly was based on comparison with other social groups and the satisfaction of health rights and needs on the basis of difference in social status. In other words, their request was for an equal outcome. The reason why the reform of the medical welfare system did not enhance equity among several types of disadvantaged elders with illness (rural residents, not cadres, not covered by MLS) was the relatively fewer benefits (such as the NRCMS) and unfair treatment during the process of receiving healthcare services. This study, from the standpoint of the disadvantaged elderly, believes that health equity is a baseline equality based on the principle of "giving priority to disadvantaged groups" (Jing 2004). The baseline equality of rights for the disadvantaged elderly (equal medical benefits and service quality) is also the basic responsibility of governments, which demonstrates that governments need to not only guarantee that old people are not excluded from the medical welfare system due to their disadvantaged status but also provide equal benefits of medical insurance and equal high-quality healthcare services compared to those received by advantaged groups.

\section{An integrated perspective on the reform: unmet needs and inadequate benefits}

After revealing the different effects of three medical insurance plans on healthcare utilization and health status in the quantitative studies, this study further analyzed the influence of the medical insurance system on outcome equity in the process of healthcare delivery through comparison of the subjective experiences of the disadvantaged elderly. In order to achieve the goal of outcome equity, an integrated approach should be introduced by government staff, decreasing the gap in welfare benefits among individuals insured by different insurance plans. This would comprise the collective action in the improvement of the medical welfare system, the pharmaceutical production and distribution system, the health-service provision system, and the long-term care system so that the unsatisfied needs and the inadequate benefits of disadvantaged elderly could be addressed. 


\section{Unmet needs of long-term care}

The reform of the medical welfare system mentioned above only focused on diseases but lacked an outcome-oriented perspective of health status for old people. The aging of the population produced a growing need for long-term care for disabled elders, the costs of which were uncovered by current medical insurance or medical-assistance systems. The disadvantaged elderly still could not afford the relatively high long-term care expenses. According to our research, the market price for a nursemaid was about 1800 to 2500 yuan per month. However, even many disadvantaged elders who had retirement pensions did not receive more than 2000 yuan per month. Their families already experienced problems due to the fact that family members (such as a daughter-in-law) who provided care also needed to work in order to support the family, which caused the quality of care to deteriorate.

Mr. T, who was living with neural muscular atrophy, relied on cheap antiinflammation drugs to control his disease. His family qualified for MLS and medical insurance, but they still could not afford the expenses for rehabilitation services. His wife said:

The doctor insists on asking him to do rehabilitation treatment. Rehabilitation costs a lot of money, so we did not go. [Question: Why don't you go to the community health center for rehabilitation, if the expense of it in the hospital is high?] He cannot walk there. It takes at least one hour to go to the community health center, which he cannot do. [Question: Have you tried to use a wheelchair to take him for rehabilitation treatment?] I have to work; I have three temporary jobs. I cannot be trapped at a job for seven or eight hours because I need to go back and take care of him. (Interviewee no. 1, old person $\mathrm{T}$ of city $\mathrm{C}$ )

When asked why their children did not provide care, old woman $\mathrm{J}$ in city $\mathrm{C}$, who was eighty-three years old, said: "They have their own family. I am embarrassed to ask them for help. This disease makes it impossible to go to the restroom by myself. I go to restroom twenty-five times per night and need a nursemaid to help. If the nursemaid is absent, my husband will help me. The situation is repeated every day. This disease cannot be totally cured, which is a big problem" (Interviewee no. 3, old person J of city C).

As the family structure transitions and intergenerational relationships change, the spouse rather than children become the primary caregiver, which is divergent from the traditional culture of filial piety. This transition increases the burden for spouses, whereas the status of widow or widower may mean a risk of lack of care. Accordingly, social policy is needed to intervene in this situation and advocate socialized long-term care provision under the background that traditional home care is weakened. The lack of long-term care services and financial systems actually led to increasing expenditures of medical insurance funds, drawing attention from medical insurance reform. However, the fund of medical insurance was set up to diversify the risk of illness, which was different from the risk of disability needed for care of elders. Otherwise, it was unfair for other insured groups. Future reform should make a clear distinction between the responsibility of the governments and that of families for healthcare and long-term care. This is an important objective for satisfying the demands for long-term care and achieving outcome-based equity in health. 


\section{Inadequate benefits and the logic of action for the disadvantaged elderly}

The inadequate benefits reflect the incomplete reform in the medical insurance systems, and the absence of outcome equity was only an untouched aspect of the reform. Old people used their own logic of action to respond to the unfairness of the reform, which was mainly reflected in the choice of healthcare services among the disadvantaged elderly. To coordinate with the medical welfare reform, the implementation of the National Essential Drugs System aimed at lowering drug prices in hospitals. However, old people still chose to buy drugs in retail pharmacies. They preferred to "buy some here and buy some there" rather than receive reimbursements from medical insurance since old people believed that drugs covered by insurance were very expensive. After carrying out the reform of zero profit in drug prices, older people still had to pay a large amount of out-of-pocket expenses even after reimbursements by medical insurance, which was more expensive than purchasing their drugs from a retail pharmacy. This attitude was evident in a focusgroup interview in county B:

LZ: You can get prescriptions from the doctors in the community health center, where the drug price is several times more expensive than that in a retail pharmacy. For instance, if the doctors prescribe drugs of eighty yuan, you pay less than forty yuan to buy the same drug in a drugstore.

WZ: If you go to that community health center, they only have a few drugs. You cannot buy what you want! (Focus group, county B)

The disadvantaged elders actively chose to resist this inequitable reform due to the inadequate benefits and unreasonable pricing of the drugs. It was an open secret that a monopoly existed in purchasing drugs through centralized bidding. Many of the covered-up secrets, such as rent seeking, were not open to the public. Some media also reported that a drug might pass through a chain of more than ten steps, from a pharmaceutical factory to the national drug reimbursement list, creating a profit of hundreds or thousands of its cost. The official drug-cost accounting was also unreliable. Centralized bidding in the new healthcare reform led to the concentration of power, which certainly increased a possibility of rent seeking. The consequences of profitdriven actions and rent seeking would be paid for by patients.

Moreover, the disease burdens of the disadvantaged elderly would not be fundamentally decreased as long as the rise in prices of medical tests and the incentive-seeking motivations of hospitals were not totally changed. Some insured elders who participated in UBMIR and NRCMS stated that "the reimbursement of drugs is too limited" and that "the benefits are not enough at all." Limited benefits directly caused many disadvantaged older people to be afraid to go to hospitals. When talking to old woman $\mathrm{M}$ in city $\mathrm{C}$, researchers asked why her husband was not getting a kidney transplant. M said: "It is costly. It requires tens of thousands of yuan to do a kidney transplant. Where can I get the money? [Question: Does medical insurance cover a large amount of the expense?] Medical insurance can pay hundreds of thousands of yuan, but we still need to pay tens of thousands. We didn't go to the hospital to reexamine the disease. Where is the money if the hospital asked us to have a surgery?" (Interviewee no. 2, couple $\mathrm{N}$ in city $\mathrm{C}$ ). 
Although the medical welfare reform in Zhejiang had explored ways to enhance formal and substantial equity, we found that the reform unsatisfied the needs and rights of the disadvantaged elderly from the perspective of social justice. These negative aspects called for much more reflection than positive aspects since the goal of equity in the reform had not been achieved. Therefore, the gap between ideal and reality, as well as the worsening trend of needs and rights of healthcare and long-term care for older people, had to be acknowledged.

\section{Policy implications and conclusion}

Development of social justice theory: a theoretical framework of "outcome-based health equity"

As mentioned above, the theory of social justice on giving priority to disadvantaged groups focuses on improving the benefits for vulnerable groups, which is also the theoretical starting point of this study. However, this study found that the disadvantaged elderly interpret health equity by comparing themselves to other groups. This is a perspective of egalitarianism that focuses the equity in health rights and narrows the gaps in relative disparities. This type of equity is not opportunity equity based on whether an old person is or is not covered by medical insurance but rather a rights-and-needs-based process and outcome equity. It is also coordination between baselines of individual rights and governmental responsibility. Therefore, this study reconstructs the theoretical framework of outcome-based health equity, which is a necessary exploration of developing a comprehensively protective mechanism of health rights and healthcare needs for the elderly (Table 3). Fortunately, China is actively exploring the integration of basic medical insurance plans in the rural and urban areas and gradually establishing the medical insurance plan for serious illnesses. However, empirical studies are still unclear whether the disparities in medical benefits are increasing or decreasing among various social groups insured by different basic medical insurance plans (Xie 2009; Qi and Li 2011). There is a long way to go before the establishment of universal medical insurance in China.

\section{Reflections on universal medical insurance: from opportunity equity to outcome equity}

Yip et al. (2012) believe that the biggest challenge of the reform in China's healthcare system is shifting the focus from investment to services that emphasize effectiveness and efficiency. To achieve the objective of health equity, the target of policy implementation should be shifted from input to output and subsequently help reach better outcomes,

Table 3 Reconstruction of a theoretical framework of the outcome-based health equity

\begin{tabular}{lll}
\hline \multicolumn{1}{c}{ Right- } \\
$\begin{array}{l}\text { based } \\
\text { equity }\end{array}$ & Opportunity equity & Definition in this study \\
& $\begin{array}{l}\text { Equal opportunity for insurance participation; } \\
\text { freely choose the level of premiums and } \\
\text { healthcare institutions }\end{array}$ & $\begin{array}{l}\text { Process and outcome equity } \\
\text { Being treated equally in the process of healthcare } \\
\text { services; equal outcomes for health status }\end{array}$ \\
$\begin{array}{l}\text { Need- } \\
\text { based } \\
\text { equity }\end{array}$ & $\begin{array}{l}\text { Reimbursements of healthcare expenditures } \\
\text { Different social groups participated in the } \\
\text { different insurance plans; complementary } \\
\text { medical insurance for serious illnesses; medical } \\
\text { assistance }\end{array}$ & $\begin{array}{l}\text { Reimbursements of healthcare expenditures and } \\
\text { long-term care costs } \\
\text { Universal medical insurance: equal needs receive } \\
\text { equal benefits; home-and-community-based } \\
\text { long-term care services }\end{array}$ \\
\hline
\end{tabular}


including improved health status and service quality, increased satisfaction of patients, and decreased financial burdens. Liu (2006) feels that universal medical insurance could change the previous principle of options and discrimination. These changes fully reflect the value of the modern welfare system, including universality, equality, civil rights, basic needs, and giving priority to health.

This study reveals the disparities in healthcare utilization and health outcomes of older people affected by different medical insurance plans, especially for older residents in rural areas insured by the NRCMS. The path-analysis model showed that there was no significant difference in the healthcare expenditures or health outcomes for NRCMS participants compared to those of the uninsured group. Outcome-based health equity appeals to the universal medical insurance system and the welfare ideology of giving priority to disadvantaged groups. Vulnerable older people have the social right to achieve an equitable health outcome after receiving fair treatment from healthcare services when compared with their advantaged counterparts with similar illness conditions. This reflects a developmental perspective from the previous focus on treatment mode to a comprehensive mode of health equity that comprises prevention, treatment, and rehabilitation.

\section{Integration of social and healthcare services in the communities: establishment of long- term care services and budget mechanisms}

The need for long-term care is excluded from the medical insurance reform, which requires the reform in medical welfare to expand from alleviating financial risk in illness to responding to comprehensive risk in health (including physical and psychological functions). One available option is to construct a home-and-community-based long-term care system since institutional care for disabled elderly is expensive and cannot be fully afforded by frail elders. Some community-based integration models have emerged in the USA, such as OnLok, Green House, California Tri-City Elder Coalition, and Age Friendly New York City, and have integrated health and social service resources in the communities. In China, the community health centers mainly provide public health and treatment services but lack psychological health, geriatrics, and other comprehensive health services. However, they are gradually starting to carry out chronic disease management. In addition, despite providing entertainment activities and household services, the aged-care system in the community administrated by Civil Affair Departments lacks professional services delivered by social workers. Accordingly, the development of socialized long-term care in the communities should be promoted through the means of strengthening the human capital training, improving quality-monitoring programs, expanding the functions of day-care centers, increasing governmental investments in social service affairs, and establishing a program of tax incentives for the social service industry ( $\mathrm{Wu}$ and $\mathrm{Xu} 2007$ ). To achieve these goals, a monitoring mechanism should be established to integrate community resources and initiate a comprehensive healthcare and long-term care system.

In regard to the source of funding, it is still controversial whether a compulsory longterm care insurance should be established (Jing 2010; Dai 2015). The long-term care insurance in Germany and Japan experienced a severe financial crisis (Cuellar and Wiener 2000; Olivares-Tirado and Tamiya 2013). Beginning in 2012, Zhejiang province was among the first to initiate the means-tested aged-care allowance program in rural and urban areas simultaneously, offering subsidies for long-term care for disabled elders living either in 
institutions or communities (Dong 2012). This is a user-centered system from the demand side and gives priority to vulnerable elderly who are severely disabled, whose families have low incomes, and older people who are living alone. Certainly, the aged-care allowance is a fiscal mechanism to support long-term care services for disabled elder in the early stage. A multilevel welfare system satisfying long-term care needs must be further established.

In the future, outcome-based health equity should be a comprehensive equity that includes long-term care and healthcare for the elderly. The objective of the medical welfare reform is not only universal coverage for all people but also universal medical insurance with equitable benefits for disadvantaged groups. This study aims to regard outcomebased health equity as the basic theory and value in future healthcare reform, which should be given a priority in policy design.

\section{Competing interests}

The authors declare that they have no competing interests.

\section{Authors' contributions}

LXT and WH carried out the research design, literature review, and data analysis and drafted the manuscript. Both authors revised and approved the final manuscript.

\section{Acknowledgements}

This research was supported by the Youth Project of the National Social Science Foundation (14CSH056) and the Major Project of National Social Science Foundation (13\&ZD163). We thank China National Committee on Ageing for providing data. We also thank Prof. Wenjiong He, Ching-man Lam, Julian Chow, and anonymous reviewers for their helpful comments.

\section{Author details}

${ }^{1}$ School of Public Affairs, Zhejiang University, Hangzhou, China. ${ }^{2}$ Department of Social Work, The Chinese University of Hong Kong, Hong Kong, Hong Kong.

Received: 31 January 2016 Accepted: 25 April 2016

Published online: 10 May 2016

\section{References}

Anderson, Ronald, and John F Newman. 2005. Societal and Individual Determinants of Medical Care Utilization in the United States. Milbank Quarterly, 83 (4):1-28.

Brown, Margaret E, Andrew B Bindman, and Nicole Lurie. 1998. Monitoring the consequences of uninsurance: a review of methodologies. Medical Care Research and Review 55(2):177-210.

Burnham, Kenneth P, and David R Anderson. 1998. Model selection and inference: a practical informationtheoretic approach. New York: Springer-Verlag.

Card, David, Carlos Dobkin, and Nicole Maestas. 2008. The impact of nearly universal insurance coverage on healthcare utilization: evidence from Medicare. American Economic Review 98(5):2242-58.

Cheng, Mei. 2004. A brief analysis on the phenomenon of inequity for old people group from the perspective of life history patterns. Population Research 3:44-51 [In Chinese].

Crocker, Lawrence. 1977. Equality, solidarity, and Rawls' maximin. Philosophy \& Public Affairs 3:262-66.

Cuellar, Alison Evans, and Joshua M. Wiener. 2000. Can social insurance for long-term care work? The experience of Germany. Health Affairs 19(3):8-25.

Dai, Weidong. 2015. The ten issues on the construction of China's long-term care system. China Soft Science 1:28-34 [In Chinese].

Daniels, Norman, Bruce P Kennedy, and Ichiro Kawachi. 1999. Why justice is good for our health: The social determinants of health inequalities. Daedalus 128(4):215-51.

Davis, Karen. 1991. Inequality and access to healthcare. The Milbank Quarterly 69(2):253-73.

Decker, Sandra L, and Dahlia K Rentier. 2004. How much might universal health insurance reduce socioeconomic disparities in health? Applied Health Economics and Health Policy 3(4):205-16.

Diehr, Paula, D Yanez, A Ash, M Hornbrook, and DY Lin. 1999. Methods for analyzing healthcare utilization and costs. Annual Review of Public Health 20(1):125-44.

Dong, Hongya. 2012. A study on the subsidy system for aged care in China. China Social Sciences Quarterly 1:55-60 [In Chinese].

Freeman, Joseph D, Srikanth Kadiyala, Janice F Bell, and Diane P Martin. 2008. The causal effect of health insurance on utilization and outcomes in adults: a systematic review of US studies. Medical Care 46(10):1023-32.

Gao, Jianmin, Lihong Ji, Ju'e Yan, and Mingqi Wang. 2011. The accessibility analysis of medical care service for the residents under three medical insurance schemes. China Health Economics 2:19-21 [In Chinese].

Ge, Yanfeng, and Sen Gong. 2007. The health reform in China: problem, reason and solution. Beijing: China Development Press [In Chinese].

Goddard, Maria, and Peter Smith. 2001. Equity of access to healthcare services: theory and evidence from the UK. Social Science \& Medicine 53(9):1149-62. 
Gwatkin, Davidson R, Adam Wagstaff, and Abdo S Yazbeck. 2005. Reaching the poor with health, nutrition and population services. Washington: World Bank Publications.

Hagenaars, Aldi JM, Klaas De Vos, and M Asghar Zaidi. 1994. Poverty statistics in the late 1980s: research based on micro-data. Luxembourg: Statistical Office of the European Communities.

Hayek, Friedrich August, and Ronald Hamowy. 2013. The constitution of liberty: the definitive edition, vol. 17. Abingdon: Routledge.

He, Wenjiong. 2013. From 'wide coverage' to 'universal coverage': three keys for social medical insurance in China. China Health Insurance 2:11-13 [In Chinese].

$\mathrm{Hu}$, Rong. 2003. Socioeconomic status and internet resources. Sociological Studies 5:58-69 [In Chinese].

Hu, Hongwei, and Dasong Deng. 2008. The implications of medical reform conception in China from the New History School. Journal of Tianshui College Administration 1:35-38 [In Chinese].

Huang, Feng, and Li Gan. 2010. Excess need or effective need? An empirical study on urban elderly health and medical insurance. Economic Research Journal 6:105-19 [In Chinese].

Huang, Nicole, Winnie Yip, Yiing-Jenq Chou, and Pen-Jen Wang. 2007. The distribution of net benefits under the National Health Insurance programme in Taiwan. Health Policy and Planning 22(1):49-59.

Jing, Tiankui. 2004. The basic equality and soft regulation of social care. Sociological Studies 6:32-40 [In Chinese].

Jing, Tao. 2010. Introducing long-term care insurance system for the current situation in China. Insurance Studies 4:77-82 [In Chinese].

Levy, Helen, and David Meltzer. 2004. What do we really know about whether health insurance affects health. In Health Policy and the Uninsured, ed. Catherine G. McLaughlin, 179-204. Washington: The Urban Institute Press.

Liang, Hong, Yuan Cheng, Ying Zhou, and Ying Zhu. 2003. An investigation of the medical service inequity for the urban residents from the perspective of medical care system. Chinese Journal of Population Science 3:39-46 [In Chinese].

Lichtenberg, Frank R. 2002. The effects of Medicare on healthcare utilization and outcomes. Forum for Health Economics \& Policy 5(1). doi:10.2202/1558-9544.1028.

Liu, Jitong. 2006. A framework for 'One policy, multiple standards' and universal basic medical insurance system. The Journal of Humanities 3:7-13 [In Chinese].

Liu, Guoen, Chunguang Cai, and Li Lin. 2011. An empirical study of the medical care and service need for the Chinese elderly. Economic Research Journal 3:95-107 [In Chinese].

Liu, Bohui, Zheng Yu, and Enhui Kou. 2012. An empirical study on the social care and medical service utilization for old people. Chinese Journal of Population Science 3:86-95 [In Chinese].

Lv, Wenjie. 2009. A study on equity of medical insurance distribution in China based on CHNS micro survey data from 1989 to 2006. Journal of Shanxi University of Finance and Economics 8:23-33 [In Chinese].

Meer, Jonathan, and Harvey S Rosen. 2004. Insurance and the utilization of medical services. Social Science \& Medicine 58(9):1623-32.

Olivares-Tirado, Pedro, and Nanako Tamiya. 2013. Trends and factors in Japan's long-term care insurance system: Japan's 10-year experience. New York: Springer Science \& Business Media.

Pavalko, Eliza K, and Jennifer Caputo. 2013. Social inequality and health across the life course. American Behavioral Scientist 8. doi:10.1177/0002764213487344.

Qi, Liangshu, and Zinai Li. 2011. The income-related mobility of health and healthcare utilization. Economic Research Journal 9:83-95 [In Chinese].

Rawls, John. 1971. A theory of justice. Cambridge: Harvard University.

Rong, Taisheng. 2009. AMOS and research methods. Chongqing: Chongqing University Press [In Chinese].

Schoen, Cathy, and MM Doty. 2004. Inequities in access to medical care in five countries: findings from the 2001 Commonwealth Fund International Health Policy Survey. Health Policy 67(3):309-22.

Sen, Amartya. 1992. Inequality reexamined. Oxford: Oxford University Press.

Wagstaff, Adam. 2000. Research on equity, poverty and health outcomes: lessons for the developing world: Health, Nutrition and Population (HNP) discussion paper. http://siteresources.worldbank.org/ HEALTHNUTRITIONANDPOPULATION/Resources/281627-1095698140167/Wagstaff-ResearchOn-whole.pdf. Accessed 20 Jan 2016

Wagstaff, Adam, and Eddy Van Doorslaer. 2000. Equity in healthcare finance and delivery. Handbook of Health Economics 1:1803-62

Wagstaff, Adam, Winnie Yip, Magnus Lindelow, William Hsiao. 2009. China's health system and its reform: A review of recent studies. Health Economics 18(S2):7-23.

Wang, Hong, Winnie Yip, Licheng Zhang, Lusheng Wang, and William Hsiao. 2005. Community-based health insurance in poor rural China: the distribution of net benefits. Health Policy and Planning 20(6):366-74.

Wang, Shaoguang. 2008. The great social transformation: the two-way movement since the 1980s. Social Sciences in China 1:129-48 [In Chinese].

Wang, Yanzhong, and Yuqi Long. 2010. Characteristics, problems and recommendations of the mid-and-low income group's medical service demand: based on the survey of 1642 families. China Journal of Health Policy 3:9-15 [In Chinese].

Whitehead, Margaret. 1992. The concepts and principles of equity and health. International Journal of Health Services 22(3):429-45.

Whitehead, Margaret. 2011. Addressing health inequalities: building on Peter Townsend's legacy. In Fighting Poverty, Inequality and Injustice: A Manifesto Inspired by Peter Townsend, ed. Alan Walker, Adrian Sinfield, and Carol Walker, 175-92. Bristol: Policy Press.

WHO. 2000. The world health report 2000: Health systems: improving performance. http://www.who.int/whr/2000/en/. Accessed 20 Jan 2016.

Wu, Bei, and Qin Xu. 2007. Community-based long-term care in urban setting: with the case study of Shanghai. Population Research 31(3):61-70 [In Chinese]. 
Xie, E. 2009. Income-related inequality of health and healthcare utilization. Economic Research Journal 2:92-105 [In Chinese].

Xu, Jie, and Shuzhuo Li. 2014. The health disadvantages and cumulative mechanism of elderly women: a study from the perspective of life course. Journal of Xi'an Jiaotong University (Social Sciences) 34(4):47-53. 68. [In Chinese].

Yip, Winnie Chi-Man, William C. Hsiao, Wen Chen, Shanlian Hu, Jin Ma, and Alan Maynard. 2012. Early appraisal of China's huge and complex health-care reforms. The Lancet 379:833-42.

\section{Submit your manuscript to a SpringerOpen ${ }^{\circ}$ journal and benefit from:}

- Convenient online submission

- Rigorous peer review

- Immediate publication on acceptance

- Open access: articles freely available online

- High visibility within the field

- Retaining the copyright to your article

Submit your next manuscript at $>$ springeropen.com 